\title{
CONSTITUINTES QUÍMICOS E TEOR DE EXTRATO AQUOSO DE CAFÉS ARÁBICA (Coffea arabica L.) E CONILON (Coffea canephora Pierre) TORRADOS
}

\author{
SIMONE MIRANDA FERNANDES ${ }^{1}$ \\ ROSEMARY GUALBERTO FONSECA ALVARENGA PEREIRA ${ }^{2}$ \\ NÍSIA ANDRADE VILLELA DESSIMONI PINTO ${ }^{3}$ \\ MARCELA CARLOTA NERY ${ }^{4}$ \\ FLÁVIA RENATA MAGALHÃES DE PÁDUA ${ }^{5}$
}

\begin{abstract}
RESUMO - Conduziu-se este trabalho com o objetivo de quantificar e caracterizar a composição química de cafés arábica e robusta de safras diferentes e seus efeitos na qualidade do café torrado. Utilizaram-se grãos de café arábica (Coffea arabica L.) da safra 88/89 e safra 2000, proveniente da região sul de Minas gerais, e o café conilon (Coffea canephora Pierre) safra 2000, proveniente do Estado do Espírito Santo. Preparou-se um "blend" na proporção $70 \%$ arábica e $30 \%$ conilon. Os cafés foram torrados (torração média - comercial), moídos e submetidos às análises físico-químicas de umidade, extrato etéreo, proteína bruta, fenólicos totais, aci-
\end{abstract}

dez titulável total, $\mathrm{pH}$, sólidos solúveis totais, extrato aquoso, açúcares totais e açúcares não-redutores. Pelos resultados, verificou-se que a acidez titulável total e o $\mathrm{pH}$ não se apresentaram com diferenças significativas, o que indica homogeneidade entre os cafés avaliados. O café arábica safra 88/89 apresentou maiores teores de extrato etéreo, indicando uma maior degradação desse café, devido provavelmente ao maior período de armazenamento. Os teores de açúcares totais e extrato aquoso não apresentaram diferenças entre os cafés estudados, quanto aos açúcares não-redutores, o café arábica de safra 88/89 mostrou-se com os menores teores e diferiu dos demais cafés.

TERMOS PARA INDEXAÇÃO: Café arábica, café conilon, composição química, safras diferentes, extrato aquoso, Coffea.

\section{CHEMICAL EVALUATION AND AQUEOUS EXTRACT OF ROASTING COFFES (Coffea arabic L.) AND CONILON (Coffea canephora Pierre)}

\begin{abstract}
The objective of this work was to quantify and to characterize the chemical composition of arabic and robust coffees of diferent crops and its effects in the quality of the toasted coffee. Arabic grains of coffee (Coffea arabic L.) of the crops 88/89 and 2000 coming from the south region of Minas Gerais state and the coffee conilon (Coffea canephora Pierre) crop 2000, coming from Espírito Santo state were used. It was prepared a blend in the proportion of $70 \%$ arabic and $30 \%$ of conilon. The coffees were toasted (medium - commercial), milled and submitted to physiochemical analyses of moisture ethereal extract, gross protein,
\end{abstract}

totals phenolics, total acidity titled, $\mathrm{pH}$, total soluble solids, aqueous extract, total and non reducing sugars. The results showed that, the total acidity titled and the $\mathrm{pH}$ did not presented significant differences which indicates homogeneity among the appraised coffees. The arabic coffee crop 88/89 presented larger contents of ethereal extract, indicating a larger degradation in this coffee probably due to the greater period of storage. The total sugars content and aqueous extract did not present differences among the studied coffees, while the non reducing sugars of the arabic coffee crop 88/89 presented the smallest contents and differing from the other coffees.

INDEX TERMS: Arabic coffee, conilon coffee, chemistry composition, crop aqueous extract, Coffea.

1. Doutoranda Departamento de Ciência dos Alimentos da UNIVERSIDADE FEDERAL DE LAVRAS/UFLA - Caixa Postal 37 - 37200-000 - Lavras, MG.

2. Professora do DCA/UFLA.

3. Professora UNIFENAS.

4. Graduanda Agronomia UFLA.

5. MS, DCA/UFLA. 


\section{INTRODUÇÃO}

O café é uma das bebidas mais aceitas e apreciadas por diversos países no mundo, por ser um produto natural, com aromas e sabores distintos. Dentre as espécies mais cultivadas, destaca-se o café arábica (Coffea arabica L.), que apresenta melhor qualidade, proporcionando bebida de maior valor comercial e alcançando preços superiores aos do robusta (Coffea canephora Pierre), cuja bebida, considerada neutra, é muito usada nas misturas ou blends e na indústria de café solúvel, sendo favorecida pelo preço mais reduzido e pela maior concentração de sólidos solúveis, o que representa um maior rendimento industrial (ILLY e VIANNI, 1996).

Sabe-se que a diversidade de ambientes no Brasil permite o cultivo do café arábica e conilon, que diferem na sua composição química devido às diferenças existentes entre as espécies, métodos de colheita, local de cultivo, processamento e armazenamento dos grãos.

As misturas de café ou blends são muito utilizadas quando se deseja manter uma uniformidade de sabor no produto. Essa prática é normalmente utilizada na obtenção de chás, cafés, vinhos, uísques, especiarias, etc. A liga ou blend é um processo de mistura de dois ou mais tipos de café. Nessa mistura podem ser adicionadas diferentes espécies, variedades e até mesmo safras, tendo como objetivo a padronização da qualidade do café (CARVALHO, 1998).

Sabe-se ainda que em praticamente todos os blends comercializados no mundo o café brasileiro entra em alguma proporção para dar a característica de “corpo” à bebida (MENDES e GUIMARÃES, 1997).

Embora o Brasil seja um dos maiores produtores mundiais de café, são poucos são os dados disponíveis sobre a qualidade do café de diferentes safras, de misturas ou blendsde cafés de diferentes espécies e de padrões de bebida distintos. Cabe ressaltar que essas misturas são muito utilizadas pelas torrefadoras para comercialização do produto e, dessa forma, torna-se necessário conhecer melhor os constituintes químicos dos cafés de diferentes espécies e safras.

Diante do exposto, com o presente trabalho objetivou-se avaliar a composição química dos grãos de cafés arábica e conilon submetidos à torração comercial, visando a uma maior informação sobre os constituintes químicos do café torrado.

\section{MATERIAL E MÉTODOS}

Foram utilizadas as espécies de café arábica (Coffea arabica) da safra 88/89 e safra 2000 provenien- tes da região sul de Minas Gerais, e o café conilon (Coffea canephora) da safra 2000, proveniente do Estado do Espírito Santo. Foi preparado ainda um blend contento $70 \%$ de café arábica e $30 \%$ de conilon. Os cafés foram submetidos a uma torração média (comercial), moídos e caracterizados física e quimicamente.

Umidade, o extrato etéreo e proteína bruta: foram determinados segundo AOAC (1990).

Fenólicos totais: foram extraídos pelo método de Goldstein e Swain (1963) utilizando como extrator o metanol $80 \%$ e identificado de acordo com o método de Folin Denis, descrito pela AOAC (1990).

Acidez titulável total: determinada por titulação com $\mathrm{NaOH} 0,1 \mathrm{~N}$, de acordo com a técnica descrita na AOAC (1990) e expressa em nível de $\mathrm{NaOH} 0,1 \mathrm{~N}$ por $100 \mathrm{~g}$ de amostra.

pH: a partir do mesmo extrato da acidez titulável total, foi medido o $\mathrm{pH}$ utilizando-se peagâmetro marca DIGIMED- DMPH-2.

Sólidos solúveis totais: determinados em refratômetro de bancada Abbe modelo 2 WAJ, conforme normas da AOAC (1990).

Açúcares totais e açúcares não-redutores: foram extraídos pelo método de Lane-Enyon, citado pela AOAC (1990) e determinados pela técnica de Somogy, adaptada por Nelson (1944).

Extrato aquoso: determinado segundo a metodologia do INSTITUTO ADOLFO LUTZ, (1985).

Utilizou-se o delineamento inteiramente casualizado (DIC), em três repetições. Os dados obtidos foram comparados pelo software SISVAR usando teste de Tukey a 5\% de probabilidade (FERREIRA, [19_]).

\section{RESULTADOS E DISCUSSÃO}

Na Tabela 1 encontram-se os valores médios de umidade, extrato etéreo, proteína bruta e polifenóis dos diferentes tipos de café torrado. O blend apresentou maior teor de umidade e o café conilon, menor teor. Os cafés arábica não diferiram entre si e diferiram dos demais cafés.

O café arábica safra 88/89 destacou-se pelo elevado teor de extrato etéreo, o que se deve provavelmente ao período de armazenamento do mesmo. O café arábica safra 2000 e o blend não diferiram quanto aos teores de extrato etéreo; entretanto, diferiram do café conilon, que apresentou menores teores. Teores ligeiramente menores para o café arábica foram verificados por Lopes (2000), estudando o comportamento de diferentes cultivares de grãos de café torrado. Segundo Amorim (1972), os óleos do grão de café durante a tor- 
ração atuam com peneira seletiva na retenção das substâncias aromáticas do grão de café, melhorando a qualidade do produto. Com base nessas afirmações, os cafés que apresentarem maior quantidade de extrato etéreo poderão apresentar melhores flavours.

Analisando os teores médios de proteína bruta (Tabela1), observa-se que o café conilon apresentou maiores teores de proteína, diferindo dos demais cafés. Os cafés arábica de safra 88/89, safra 2000 e o blend não diferiram entre si. Esses dados estão condizentes com aqueles encontrados por Fernandes et al. (2000) em diferentes padrões de bebida e blends de cafés arábica torrados comercialmente.

A degradação de proteínas é proporcional ao grau de torração, que varia de 20 a $30 \%$ em torração médias e em torno de $50 \%$ nas escuras, sendo dependente também da composição inicial e ainda da espécie e variedade, como citam Illy e Vianni (1996). A torração também leva à desnaturação e à degradação das proteínas, que podem ser observadas a partir das mudanças que ocorrem na composição dos aminoácidos, com o aumento dos termoestáveis como alanina, ácido glutâmico, glicina, leucina, fenilalanina e valina, e à diminuição de outras, como arginina, cisteína, serina e treonina. Esses aminoácidos encontram-se envolvidos em uma série de reações que darão origem aos compostos que formam as substâncias voláteis, estas responsáveis pelo aroma do café.

O café conilon apresentou os maiores teores de polifenóis, diferindo assim dos demais cafés, enquanto o café arábica safra 2000 apresentou menores teores. Resultados semelhantes foram verificados por Fernandes et al. (2000) em padrões de bebida de cafés torrados.

Segundo Illy e Vianni (1996), o teor de polifenóis varia em função da temperatura de torração e com a variedade do café. Esse composto pode ainda indicar uma maior deterioração desses cafés com redução da qualidade.

Os dados referentes aos teores de acidez titulável total, $\mathrm{pH}$ e sólidos solúveis totais do café torrado estão na Tabela 2.

TABELA 1 - Teores de umidade (\%), extrato etéreo, proteína bruta e polifenóis (\%) de diferentes tipos de café torrado.

\begin{tabular}{lcccccc}
\hline & Arábica & Arábica & Blend & Conilon & C.V(\%) \\
& Safra 88/89 & Safra 2000 & & & & \\
Umidade & $2,08 \mathrm{a} \mathrm{b}$ & $2,37 \mathrm{a} \mathrm{b}$ & $2,55 \mathrm{a}$ & 1,54 b & 8,03 \\
Extrato etéreo & $17,58 \mathrm{a}$ & $17,02 \mathrm{~b}$ & $15,91 \mathrm{~b}$ & 10,68 & $\mathrm{c}$ & 9,17 \\
Proteína bruta & $15,36 \mathrm{~b}$ & $15,59 \mathrm{~b}$ & $15,41 \mathrm{~b}$ & $17,18 \mathrm{a}$ & 6,11 \\
Polifenóis & $4,31 \mathrm{~b} \mathrm{c}$ & $4,16 \mathrm{c}$ & $4,79 \mathrm{~b}$ & $6,18 \mathrm{a}$ & 8,50 \\
\hline
\end{tabular}

*Letras diferentes na horizontal indicam existência de diferença significativa entre as médias, pelo teste de Tukey ao nível de $5 \%$ de probabilidade.

TABELA 2 - Teores de acidez titulável total (mL de NaOH.100g-1 ${ }^{1}$, pH e sólidos solúveis totais (\%) bs de diferentes tipos de café torrado.

\begin{tabular}{|c|c|c|c|c|c|}
\hline & $\begin{array}{c}\text { Arábica } \\
\text { Safra 88/89 }\end{array}$ & $\begin{array}{c}\text { Arábica } \\
\text { Safra } 2000\end{array}$ & Blend & Conilon & C.V $(\%)$ \\
\hline Acidez & $172,22 \mathrm{a}$ & $166,67 \mathrm{a}$ & $162.50 \mathrm{a}$ & $172,22 \mathrm{a}$ & 6,12 \\
\hline $\mathrm{pH}$ & $6,03 \mathrm{a}$ & $5,87 \mathrm{a}$ & $6,02 \mathrm{a}$ & $5,93 a$ & 4,08 \\
\hline SST & $26,97 \quad b$ & $28,17 \mathrm{a} \mathrm{b}$ & $27,49 \quad b$ & $31,39 a$ & 9,15 \\
\hline
\end{tabular}

* Letras diferentes na horizontal indicam existência de diferença significativa entre as médias, pelo teste de Tukey, ao nível de $5 \%$ de probabilidade. 
Analisando os dados de acidez titulável (Tabela 2), observa-se que os diferentes cafés torrados não apresentaram diferenças significativas. Os teores mostraram-se inferiores aos citados por Pinto (2002) em seis padrões de bebida do café e submetidos a dois grãos de torração, cujos teores variaram de 280,00 a 350,00 mL de NaOH.100g-1 .

Sabe-se que o incremento na acidez com a torração se deve à formação de ácidos; no entanto, a severidade da torração diminui a acidez da bebida por destruir ácidos clorogênicos que se encontram ligados à matriz do grão (NAKABAYASHI, 1978). A quantidade de ácidos carboxílicos do café torrado depende da variedade e espécie de café, que decresce com a torração e também com métodos aplicados. A torração aumenta os ácidos voláteis, principalmente com degradação dos carboidratos. A concentração dos ácidos voláteis chega ao máximo com a torração média, descrece com o aumento da torração, devido a sua volatilização (CLIFFORD, 1975).

Pelos dados da tabela 2, verificam-se os valores de $\mathrm{pH}$ para os diferentes cafés torrado. Os valores encontrados são superiores aos citados pela OIC (1992), de 5,31 a 5,63 para amostras de cafés comerciáveis, e aos verificados por Lopes (2000), de 5,15 a 5,56 em diferentes cultivares de café arábica. As variações do $\mathrm{pH}$ com a torração podem ser de muita importância na aceitação do produto pelo consumidor e indicam que o $\mathrm{pH}$ ideal deve estar entre 4,95 a 5,20, tornando o café palatável, sem excesso de amargor ou acidez.

Houve variação significativa nos teores de sólidos solúveis totais, o café conilon destacou-se pelo seu elevado teor, seguida do café arábica safra 2000; entretanto, o café arábica safra 88/89 demonstrou os menores teores. Esses resultados concordam com os verificados por Barrios (2001), que em cafés do sul de Minas Gerais encontrou teores de sólidos solúveis de 27,75 a
$30,00 \%$, as quais não apresentaram diferenças significativas entre si. As diminuições no teor de sólidos solúveis foram relatadas por Sabbagh et al. (1976) como consequiência da perda de ácidos orgânicos e da volatilização de alguns compostos no processo pirolítico de torração. Os açúcares totais não apresentaram diferenças entre os cafés estudados, conforme os dados apresentados na Tabela 3. Os resultados do presente trabalho mostraram-se com variações, quando comparados aos da literatura, sendo inferiores aos valores encontrados por Lopes (2000), no café arábica de diferentes cultivares, no qual encontrou teores de 3,20 a $2,14 \%$ de açúcares totais em grãos com torração clara, e próximos aos menores teores encontrados por Pinto et al. (2001), em grãos do café arábica com torração média, cujos teores variaram de 0,77 a 1,63\% de açúcares totais.

As diferenças entre os valores da literatura e os estudados podem ser atribuídos a uma maior degradação desses açúcares no processo de torração, pois, segundo Shankarayana et al. (1974), os açúcares participam juntamente com os aminoácidos e proteínas de reações de Maillard e caramelização durante o processo de torração, então, se degradam e originam vários compostos voláteis do café torrado.

O blend apresentou o maior percentual de açúcares redutores e diferiu dos demais cafés. Quanto aos teores de açúcares não-redutores, o café arábica de safra 88/89 mostrou-se com os menores teores e diferiu dos demais estudados.

Os percentuais encontrados são próximos à faixa encontrada por Pinto et al. (2001), de 0,16 a $0,25 \%$ para os açúcares redutores e de 0,40 a 0,99 para os açúcares não-redutores, em padrões de bebida do café arábica submetido à torração média.

TABELA 3 - Teores médios de extrato aquoso (\%), açucares totais (\%), glicose (\%) e sacarose (\%) de cafés torrados.

\begin{tabular}{lccccc}
\hline & $\begin{array}{c}\text { Arábica } \\
\text { Safra 88/89 }\end{array}$ & $\begin{array}{c}\text { Arábica } \\
\text { Safra 2000 }\end{array}$ & Blend & Conilon & CV(\%) \\
\hline Extrato Aquoso & $27,64 \mathrm{a}$ & $27,15 \mathrm{a}$ & $28,44 \mathrm{a}$ & $30,96 \mathrm{a}$ & 13,54 \\
Aç. Totais & $0,49 \mathrm{a}$ & $0,71 \mathrm{a}$ & $0,66 \mathrm{a}$ & $0,58 \mathrm{a}$ & $\ldots .15,42$ \\
Glicose & $0,18 \mathrm{~b}$ & $0,27 \mathrm{a}$ & $0,26 \mathrm{a}$ & $0,29 \mathrm{a}$ & 18,92 \\
Sacarose & $0,30 \mathrm{~b}$ & $0,37 \mathrm{~b}$ & $0,59 \mathrm{a}$ & $0,28 \mathrm{~b}$ & 33,96 \\
\hline
\end{tabular}

* Letras diferentes na horizontal indicam existência de diferença significativa entre as médias, pelo teste de Tukey ao nível de $5 \%$ de probabilidade. 
Segundo Amorim (1972), aparentemente os açúcares não apresentam relação direta com as propriedades sensoriais da bebida; no entanto, estão associados à formação da cor característica do café torrado, a produtos caramelizados e a substâncias responsáveis pelo sabor e aroma.

Nenhuma diferença significativa foi encontrada quanto aos teores de extrato aquoso nos diferentes cafés estudados. O café conilon mostrou-se com o mais alto teor $(39,96 \%)$, seguido pelo blend $(28,44 \%)$ e pelos cafés arábicas safra 88/89 e safra $2000(27,64 \%$ e $27,15 \%)$, respectivamente. Os dados verificados no presente trabalho estão de acordo com a faixa encontrada por Pedro et al. (1996) em cafés comerciais variando entre 25 e $38,98 \%$.

O extrato aquoso do café torrados e moído representa a quantidade de subst6ancias capazes de se solubilizarem em água fervente. Substâncias estranhas podem ser responsáveis pela obtenção de maiores valores para esse extrato, assim como substâncias minerais podem causar reduções nesses valores (ALVES et al. 1989). Outro aspecto citado por esses autores como causador de reduções nesses valores são condições adversas ao produto.

\section{CONCLUSÕES}

Variação significativa ocorreram nos teores de todos os parâmetros estudados, exceto para a acidez titulável total e o $\mathrm{pH}$.

O café arábica safra 88/89 apresentou maiores teores de extrato etéreo, provavelmente, ao período de armazenamento do mesmo.

Os teores de açúcares totais e extrato aquoso não apresentaram diferenças entre os cafés estudados, não sendo possível uma avaliação mais detalhada.

O café arábica de safra 88/89 mostrou-se com os menores teores de açúcares não-redutores e blend apresentou o maior percentual de açúcares redutores.

\section{REFERÊNCIAS BIBLIOGRÁFICAS}

ALVES, G.; CAMPOS, C. M. T.; MORETTO, E.; PHILIPPI, J. M. S.; ARCHER, R. M.; GOULART, R.; GOULART, M. M. Controle de qualidade dos cafés comercializados em Santa Catarina no segundo semestre de 1986. Boletim Bromasc, [S.1.], v. 1, n. 2, p. 72-80, 1989.

AMORIM, H. V. Relação entre alguns compostos orgânicos do grão do café verde com a qualidade da bebida. 1972. 136 f. Tese (Doutorado em Bioquímica)
- Escola Superior de Agricultura Luiz de Queiroz, Piracicaba, 1972.

ASSOCIATION OF OFFICIAL ANALYTICAL CHEMISTS. Official methods of the Association of Official Analytical Chemists. 15. ed. Washington, 1990. $684 \mathrm{p}$.

BARRIOS, B. B. E. Caracterização física, química, microbiológica e sensorial de cafés (Coffea arabica $\mathrm{L}$.) da região Alto Rio Grande - Sul de Minas Gerais. 2001.72 p. Dissertação (Mestrado em Ciência dos Alimentos) - Universidade Federal de Lavras, Lavras, 2001.

CARVALHO, V. D. de. Cafeicultura empresarial: produtividade e qualidade. Lavras: UFLA/FAEPE, 1998. 73 p.

CLIFFORD, M. N. The composition of green and roasted coffee bens. Process Biochemistry, London, v. 2, n. 24, p. 20-23, Mar. 1975.

FERNANDES, S. M.; PINTO, N. A. V. D.; PEREIRA, R. G. F. A.; CARVALHO, V. D. de. Efeito da composição química de padrões de bebida de cafés torrados comercialmente provenientes de duas cooperativas do sul de Minas Gerais. In: SIMPÓSIO DE PESQUISA DOS CAFÉS DO BRASIL, 1., 2000, Poços de Caldas. Resumo... Poços de Caldas: [s.n.], 2000. p. 684-683.

FERREIRA, D. F. Programa Sisvar: sistema de análises de variânica. Versão 3.04. [S.1.: s.n.], [19__].

GOLDSTEIN, J. L.; SWAIN, T. Changes in tannins in ripening fruits. Phytochemistry, Oxford, v. 2, n. 4, p. 371-382, Dec. 1963.

ILLY, A.; VIANNI, R. Espresso coffee: the chemistry of quality. San Diego: Academic, 1996. 253 p.

INSTITUTO ADOLFO LUTZ. Normas analíticas, métodos químicos e físicos para análise de alimentos. 3. ed. São Paulo, 1985. v. 1.

LOPES, L. M. V. Avaliação da qualidade de grão crus e torrados de cultivares de cafeeiro (Coffea $a$ rabica L.). Lavras: UFLA, 2000. 95 p.

MENDES, A. N. G.; GUIMARÃES, R. J. Economia cafeeira: o agribusiness. In: Cafeicultura empresarial: produtividade e qualidade. Lavras: UFLAFAEPE, 1997. 59 p. 
NAKABAYASHI, T. Changes of organic acids and $\mathrm{pH}$ roast of coffee. Journal Japanise Society Food Science Technology, [S.1.], v. 25, p. 142-146, 1978.

NELSON, N. A photometric adaptation of Somogy method for determination of glucose. Journal of Biological Chemists, Baltimore, v. 153, n. 1, p. 375384, 1944.

ORGANIZACION INTERNACIONAL DEL CAFÉ. EI despulpado del café por medio de desmucilaginadoras mecanicas sin proceso de fermentación y su efecto en la calidade de bebida de café producido en la región de Apucarana en el estado de Paraná en Brasil: 1992. [S.1.: s.n.], 1992. (Reporte de Evalución Sensorial).

PEDRO, N. A. R.; BARTOLATO, M. I. C.; FREITAS, V. P. S.; CHIARINI, P. F. T. Avaliação da aulaidade do café torrado e moído processado na região de campinas, estado de São Paulo. Revista do Instituto Adolfo Lutz, São Paulo, v. 5, n. 1, p. 113-117, 1996.
PINTO, N. A. V. D. Avaliação química e sensorial de diferentes padrões de bebida do café arábica cru e torrado. 2002. 92 p. Tese (Doutorado em Ciência dos Alimentos) - Universidade Federal de Lavras, Lavras, 2002.

PINTO, N. A. V. D.; PEREIRA, R. G. F. A.; FERNANDES, S. M.; CARVALHO, V. D. de. Açúcares e sólidos solúveis em bebidas e blends de cafés torrados tipo expresso. In: SIMPÓSIO DE PESQUISAS DOS CAFÉS DO BRASIL, 2., 2001, Vitória. Resumos... Rio de janeiro: EMBRAPA, 2001. p. 101.

SABBAGH, N. K.; YOKOMIZO, Y. Efeito da torração sobre algumas propriedades químicas de cafés Arábica e Robusta. Coletânea do Instituto de Tecnologia de Alimentos, Campinas, v. 7, p. 147-161, 1976.

SHANKARAYANA, M. L.; RAGHAVEN, B.; ABRAHAM, O.; NATARAJAN, C. P. Complex nature of coffee aroma. Indian Coffee, Bangalore, v. 38, n. 4, p. 84-92, Apr. 1974. 